
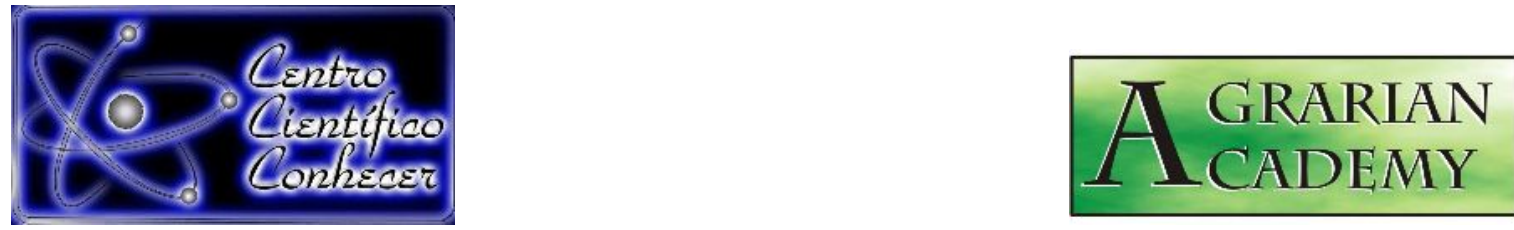

\title{
SELEÇÃO DE DESCRITORES DE SEMENTES DE MARACUJAZEIRO AZEDO UTILIZANDO FENOTIPAGEM DIGITAL
}

Amanda Fernanda Nunes Ferreira1, Willian Krause ${ }^{2}$, Alexandro Cézar Faleiro $^{3}$, Anderson Fernandes de Miranda ${ }^{4}$, Amanda Justino Acha ${ }^{5}$

1Mestre em Genética e Melhoramento de Plantas, Universidade do Estado do Mato Grosso campus de Tangará da Serra - MT, Brasil. e-mail: amanda.afnf@gmail.com

2 Doutor em genética e melhoramento de plantas, Professor adjunto da Universidade do

Estado de Mato Grosso UNEMAT - Campus de Tangará da Serra- MT, Brasil

${ }^{3}$ Doutor em Ciências, Professor adjunto da Universidade do Estado de Mato Grosso UNEMAT - Campus de Tangará da Serra- MT, Brasil

${ }^{4}$ Doutor em Genética e Melhoramento, Professor adjunto da Universidade do Estado de Mato Grosso UNEMAT - Campus de Tangará da Serra- MT, Brasil

${ }^{5}$ Doutoranda em produção vegetal pela Universidade Estadual do Norte Fluminense, Campos dos Goytacazes - RJ, Brasil.

Recebido em: 19/11/2018 - Aprovado em: 14/12/2018 - Publicado em: 25/12/2018 DOI: 10.18677/Agrarian_Academy_2018B17

\section{RESUMO}

O objetivo desse trabalho foi selecionar descritores de sementes em maracujazeiro obtidos por meio de análise digital de imagem utilizando os componentes principais. Para isto, foram analisados 95 descritores mensurados a partir da análise digital de imagens em sementes de 35 famílias de irmãos completos de maracujazeiro azedo. Foram avaliadas 50 sementes por família. Para avaliação dos descritores foi utilizado o método dos componentes principais e a seleção foi realizada com base em descartar a variável como maior coeficiente em cada componente com autovalor menor que 0,70 , de acordo com as pressuposições de Jolliffe e Mardia. Foi possível reduzir o número de descritores, sendo selecionados cinco de cor, seis de geometria e seis de textura. A análise digital de imagem é uma ferramenta viável e eficiente na mensuração de descritores de sementes no maracujazeiro azedo.

PALAVRAS-CHAVE: análise digital de imagem, componentes principais, Passiflora edulis L.

\section{SELECTION OF DESCRIPTORS OF SEEDS OF PASSION FRUIT SOUR USING DIGITAL PHENOTYPING}

\footnotetext{
ABSTRACT

The objective of this work was to select seed descriptors in passion fruit obtained through digital image analysis using the main components. For this, we analyzed 95 descriptors measured from the digital image analysis in seeds of 35 families of complete sibs of passion fruit sour. Fifty seeds per family were evaluated. For the evaluation of the descriptors, the principal component method was used and the AGRARIAN ACADEMY, Centro Científico Conhecer - Goiânia, v.5, n.10; p. 1812018
} 
selection was performed based on discarding the variable as the highest coefficient in each component with an eigenvalue lower than 0.70 , according to the assumptions of Jolliffe and Mardia. It was possible to reduce the number of descriptors, being selected five of color, six of geometry and six of texture. Digital image analysis is a viable and efficient tool in the measurement of seed descriptors in sour passion fruit. KEYWORDS: Digital image analysis, Main components, Passiflora edulis L.,

\section{INTRODUÇÃO}

A fenotipagem pode ser realizada com o emprego de descritores morfoagronômicos, sejam eles quantitativos ou qualitativos. Várias partes da planta como os relacionados a folha, flor, fruto, sementes, entre outros são utilizadas como descritores morfológicos. No caso da semente, ela é o óvulo fecundado das plantas superiores e sua importância está relacionada a reprodução e dispersão (GUSTIN; SETTLES, 2015). Portanto, selecionar descritores voltados para as características das sementes é mais uma estratégia relevante para auxiliar na seleção de genótipos em programas de melhoramento genético.

Para isso novas tecnologias para ambientes controlados como técnicas de espectroscopia, termografia, tomografia, fluorescência, discriminação por isótopos e imagens digitais estão sendo empregadas visando a acurácia e rapidez das mensurações fenotípicas para melhor caracterização (SANTOS; YASSITEPE, 2014).

Vários sistemas já foram desenvolvidos como ferramentas auxiliares nos processos de seleção de sementes tais como a técnica de análise de sementes utilizando Raio-X e o SVIS (Seed Vigor Imaging System), que foi desenvolvido pela Universidade do Estado Norte Americano Ohio (SILVA et al., 2012). Desde então, as técnicas de análises de imagens têm ficado cada vez mais elaboradas e eficientes.

A análise digital é considerada um método viável além de conseguir resultados rápidos, é um método com baixo custo, podendo ser utilizado em diversas áreas, como as indústrias de alimentos e na agricultura (ANDRADE et al., 2016). No Brasil, com objetivo de realizar a captura de imagens, histogramas, gráficos que facilitem a análise de imagens das sementes e plântulas, foi desenvolvido o equipamento SAS (Sistema de Análise de Sementes), pela empresa Tbit em 2011.

Assim, características que nunca foram mensuradas antes ou somente em situações específicas estão começando a ser medidas com maior frequência e de maneira fácil como as características relacionadas ao tamanho, cor, forma e textura da semente (FIORANI; SCHURR, 2013). A análise digital de imagem de sementes vem sendo utilizada para a identificação de cultivares, determinação de sementes de diferentes cores, danos mecânicos e de classificação de diferentes tamanhos de sementes (VENORA et al., 2009; KARA et al., 2013; PINTO et al., 2015; ANDRADE et al., 2016).

Descritores obtidos via análise digital de imagens tem sido utilizado para quantificação da variabilidade genética em programas de melhoramento como o da goiabeira (KRAUSE et al., 2017). Entretanto, ainda não se tem informações sobre a utilização de imagem digital para seleção de descritores utilizando características da semente como tamanho, forma, textura e cor no maracujazeiro azedo. Desta forma, o objetivo desse trabalho foi selecionar descritores de sementes em maracujazeiro azedo, obtidos a partir da fenotipagem digital, utilizando os componentes principais. 


\section{MATERIAL E METÓDOS}

Foram analisadas sementes de 35 famílias de irmãos completos (FIC) de maracujazeiro azedo provenientes do programa de melhoramento da Universidade do Estado de Mato Grosso (UNEMAT). As sementes foram coletadas das FIC plantadas na área experimental da UNEMAT, no município de Tangará da Serra-MT, entre os meses de abril e maio de 2016.

Os frutos de cada FIC foram seccionados transversalmente e as sementes retiradas, junto com os tecidos placentários, com auxílio de uma colher. O material foi transferido para uma peneira de nylon para retirada do arilo. As sementes foram friccionadas contra a peneira e lavadas em água corrente para separação do material placentário. Logo após as sementes foram secas em ambiente natural para retirada do excesso de umidade e posteriormente foram limpas, etiquetadas e armazenadas em geladeira com temperatura controlada.

A análise digital de sementes foi realizada em junho de 2016 no setor de Tecnologia de Sementes da Universidade Estadual Norte Fluminense (UENF) em Campos dos Goytacazes- RJ. Foram utilizadas 50 sementes por FIC. A captura e análise digital das imagens das sementes foram realizadas com as sementes sem arilo. As sementes foram colocadas sobre uma bandeja de acrílico transparente, de maneira que as sementes não se encostassem. Posteriormente a bandeja foi inserida na câmara de captação do SAS (Sistema de Análise de Sementes) para serem analisadas. O SAS fornece uma planilha com valores médios de cada FIC para os descritores analisados.

Foram avaliados 95 descritores de sementes, sendo 34 de cor, 34 de geometria e 27 de textura. Os 34 descritores relacionados a cor foram: cor abaixo do otsu canal azul (C1); cor abaixo do otsu canal verde (C2); cor abaixo do otsu canal vermelho (C3); cor abaixo do otsucielab a (C4); cor abaixo do otsucielab b (C5); cor abaixo do otsucielab I (C6); cor acima do otsu canal azul (C7); cor acima do otsu canal verde (C8); cor acima do otsu canal vermelho (C9); cor acima do otsucielab a (C10); cor acima do otsucielab b (C11); cor acima do otsucielab I (C12); cor brilho (C13); cor cielab a (C14); cor cielab b (C15); cor cielab dispersão (C16); cor cielab dispersão de a (C17); cor cielab dispersão de b (C18); cor cielab dispersão de I (C19); cor cielab I (C20); cor concentração da matriz (C21); cor dominância cinza escuro (C22); cor dominância laranja (C23); cor dominância preta (C24); cor dominância vermelha (C25); cor matiz (C26); cor media canal azul (C27); cor media canal verde (C28); cor media canal vermelho (C29); cor predominante canal azul (C30); cor predominante canal verde (C31); cor predominante canal vermelho (C32); cor saturação (C33); cor variância da matiz (C34).

Para geometria, os 34 descritores analisados foram: geometria afinamento (G1); geometria área (G2); geometria área convexa (G3); geometria circularidade (G4); geometria circularidade por fato de forma (G5); geometria circularidade por ffcg (G6); geometria circularidade por ffcm (G7); geometria complexidade da forma (G8); geometria compressão (G9); geometria convexidade do contorno (G10); geometria deformação do contorno (G11), geometria diâmetro do contido (G12); geometria diâmetro máximo (G13); geometria diâmetro lateral (G14); geometria diâmetro mínimo (G15); geometria distancias convexas (G16); geometria esfericidade de forma (G17); geometria esfericidade de forma modificada (G18); geometria mudança no perímetro (G19); geometria número de quinas por harris (G20); geometria número de quinas por susan (G21); geometria perímetro (G22); geometria perímetro convexo (G23); geometria quociente de aspecto (G24); geometria retângulos circunscritos maior área (G25); geometria retângulos circunscritos maior aresta 
(G26); geometria retângulos circunscritos maior perímetro (G27); geometria retângulos circunscritos média das maiores arestas (G28); geometria retângulos circunscritos média das menores arestas (G29); geometria retângulos circunscritos menor área (G30); geometria retângulos circunscritos menor aresta (G31); geometria retângulos circunscritos menor perímetro (G32); geometria retângulos circunscritos perímetro médio (G33); geometria: solidez contorno (G34).

Com relação a textura, foram analisados 27 descritores: textura: fourier medias das fases (T1); textura haralick contraste (T2); textura haralick correlação (T3); textura haralick dissimilaridade (T4); textura haralick energia (T5); textura haralick entropia (T6); textura haralick homogeneidade (T7); textura haralick média (T8); textura haralick variância (T9); textura lawsek(T10); textura lawsle (T11); textura lawslr (T12); textura lawsls (T13); textura lawslw (T14); textura lawsrw (T15); textura lawssr (T16); textura lawssw (T17); textura runlenghtgld (T18); textura runlenghtglnu (T19); textura runlenghthgre (T20); textura runlenghtlre (T21); textura runlenghtlrhge (T22); textura runlenghtrlnu (T23); textura runlenghtsre (T24); textura runlenghtsrhge (T25); textura sfm: medida do espaço de frequência (T26); textura sfm: medida do espaço de frequência (T27).

Foi efetuada a análise de componentes principais com o emprego da distância euclidiana média padronizada, uma vez que as FIC se encontram estabelecidas sem obedecer a nenhum delineamento experimental (CRUZ et al., 2012).

A análise de componentes principais vem se destacando como a metodologia mais empregada na seleção de descritores pois além de identificar os caracteres mais importantes na contribuição de variação total disponível entre os indivíduos analisados, fornece indicação para eliminar os que pouco contribuem sendo uma técnica da estatística multivariada que consiste em transformar um conjunto de variáveis originais em outro conjunto de variáveis de mesma dimensão denominadas de componentes principais.

Para seleção de descritores, foi adotado o critério de descartar a variável com o maior coeficiente em cada componente com autovalor menor que 0,70 , de acordo com as pressuposições de Jolliffe (1972, 1973) e Mardia et al. (1979). Desta forma, foi indicado para descarte todo caráter que apresentou maior coeficiente de ponderação em valor absoluto (autovetor), no componente principal de autovalor menor, partindo do último componente até aquele cujo autovalor não excedeu 0,70. Para a realização das análises foi utilizado o programa Genes (CRUZ; GENES, 2013).

\section{RESULTADOS E DISCUSSÃO}

Ao analisar as estimativas dos autovalores associados aos componentes principais em relação os descritores de cor e suas respectivas variâncias relativas e acumuladas, percebe-se que os três primeiros componentes conseguiram explicar $89,88 \%$ da variância acumulada, com a primeira variável explicando $52,50 \%$, a segunda $26,16 \%$ e a terceira $11,22 \%$ (Tabela 1 ). De acordo com o método de Jolliffe (1972, 1973), cinco descritores foram selecionados, sendo: abaixo do otsu canal vermelho (C3), cor abaixo do otsucielab a (C4), cor cielab b (C15), cor cielab dispersão de b (C18) e cor matiz (C26).

A distribuição da variância associada ao número de descritores está concentrada nos três primeiros componentes principais, tanto para o grupo de variáveis de cor, geometria e textura sendo a representação gráfica tridimensional como mais adequada (CRUZ et al., 2012). Lucio et al. (2013), utilizaram a análise de 
componentes principais para identificar os caracteres que mais merecem atenção em experimentos com a cultura do maracujazeiro azedo e verificou suas relações com o caractere dependente principal com a produção total de frutos.

Quando se avalia o descarte preliminar efetuado pela seleção direta, verificase que o primeiro descritor indicado foi $\mathrm{C} 19$, apresentando o maior coeficiente de ponderação em módulo com o último componente principal $(-0,4585)$, seguido pelos descritores C6, C12, C7, C29, cujos maiores autovetores em módulo ocorreram nos componentes principais $33,32,31$ e 30 , respectivamente. Nesse procedimento, 29 descritores foram considerados redundantes.

TABELA 1. Estimativas dos autovalores associados aos componentes principais (CP) e suas variâncias relativas e acumuladas, obtidas dos 34 caracteres de cor avaliados em sementes de maracujazeiro azedo

\begin{tabular}{cccc}
\hline CP & Autovalor & $\begin{array}{c}\text { Variância } \\
\text { relativa }\end{array}$ & $\begin{array}{c}\text { Variância } \\
\text { acumulada }\end{array}$ \\
\hline 1 & 17,85 & 52,50 & 52,50 \\
2 & 8,89 & 26,16 & 78,66 \\
3 & 3,81 & 11,22 & 89,88 \\
4 & 1,38 & 4,07 & 93,95 \\
5 & 0,74 & 2,16 & 96,11 \\
6 & 0,44 & 1,30 & 97,41 \\
7 & 0,31 & 0,91 & 98,32 \\
8 & 0,17 & 0,50 & 98,82 \\
9 & 0,12 & 0,35 & 99,17 \\
10 & 0,10 & 0,28 & 99,45 \\
11 & 0,06 & 0,18 & 99,64 \\
12 & 0,04 & 0,13 & 99,77 \\
13 & 0,03 & 0,08 & 99,85 \\
14 & 0,02 & 0,05 & 99,89 \\
15 & 0,01 & 0,03 & 99,93 \\
16 & 0,01 & 0,02 & 99,95 \\
17 & 0,01 & 0,02 & 99,97 \\
18 & 0,01 & 0,02 & 99,98 \\
19 & 0,00 & 0,01 & 99,99 \\
20 & 0,00 & 0,01 & 99,99 \\
21 & 0,00 & 0,00 & 100,00 \\
22 & 0,00 & 0,00 & 100,00 \\
23 & 0,00 & 0,00 & 100,00 \\
24 & 0,00 & 0,00 & 100,00 \\
25 & 0,00 & 0,00 & 100,00 \\
26 & 0,00 & 0,00 & 100,00 \\
27 & 0,00 & 0,00 & 100,00 \\
28 & 0,00 & 0,00 & 100,00 \\
29 & 0,00 & 0,00 & 100,00 \\
30 & 0,00 & 0,00 & 100,00 \\
31 & 0,00 & 0,00 & 100,00 \\
32 & 0,00 & 0,00 & 100,00 \\
33 & 0,00 & 0,00 & 100,00 \\
34 & 0,00 & 0,00 & 100,00 \\
\hline
\end{tabular}


Em relação aos descritores de geometria, os três primeiros componentes principais conseguiram explicar $79,25 \%$ da variação (Tabela 2). Foram selecionados seis descritores sendo G8, G14, G18, G23, G24, G2.

TABELA 2. Estimativas dos autovalores associados aos componentes principais $(\mathrm{CP})$ e suas variâncias relativas e acumuladas, obtidas dos 34 caracteres de geometria avaliados em sementes de maracujazeiro azedo

\begin{tabular}{cccc} 
CP & Autovalor & $\begin{array}{c}\text { Variância } \\
\text { relativa }\end{array}$ & $\begin{array}{c}\text { Variância } \\
\text { acumulada }\end{array}$ \\
1 & 15,70 & 44,30 & 44,30 \\
2 & 9,78 & 28,69 & 72,99 \\
3 & 2,13 & 6,26 & 79,25 \\
4 & 1,83 & 5,36 & 84,61 \\
5 & 1,66 & 4,88 & 89,49 \\
6 & 1,13 & 3,33 & 92,82 \\
7 & 0,66 & 1,94 & 94,75 \\
8 & 0,54 & 1,57 & 96,32 \\
9 & 0,27 & 0,80 & 97,12 \\
10 & 0,26 & 0,77 & 97,89 \\
11 & 0,19 & 0,55 & 98,44 \\
12 & 0,11 & 0,32 & 98,76 \\
13 & 0,07 & 0,22 & 98,98 \\
14 & 0,06 & 0,16 & 99,14 \\
15 & 0,05 & 0,13 & 99,27 \\
16 & 0,04 & 0,12 & 99,39 \\
17 & 0,03 & 0,10 & 99,49 \\
18 & 0,03 & 0,08 & 99,57 \\
19 & 0,03 & 0,08 & 99,65 \\
20 & 0,02 & 0,06 & 99,71 \\
21 & 0,01 & 0,04 & 99,75 \\
22 & 0,01 & 0,04 & 99,79 \\
23 & 0,01 & 0,03 & 99,82 \\
24 & 0,01 & 0,02 & 99,84 \\
25 & 0,01 & 0,02 & 99,86 \\
26 & 0,01 & 0,02 & 99,87 \\
27 & 0,00 & 0,01 & 99,88 \\
28 & 0,00 & 0,00 & 99,88 \\
29 & 0,00 & 0,00 & 99,89 \\
30 & 0,00 & 0,00 & 99,89 \\
31 & 0,00 & 0,00 & 99,89 \\
32 & 0,00 & 0,01 & 99,89 \\
33 & 0,01 & 0,04 & 99,94 \\
34 & 0,02 & 0,06 & 100,00 \\
\hline & & &
\end{tabular}

A análise de componentes principais foi utilizada por Medina et al. (2010), para a análise de um conjunto de 38 descritores de sementes compostas por oito descritores geométricos, 20 descritores morfológicos, quatro descritores fractais e seis de cor obtidas de 25 variedades de quinoa (Chenopodium quinoa Willd). O primeiro componente principal (CP1) explicou $47,7 \%$ da variação total, o segundo AGRARIAN ACADEMY, Centro Científico Conhecer - Goiânia, v.5, n.10; p. 1862018 
mais o primeiro $65,8 \%$ e usando o somatório dos três primeiros componentes foi possível explicar $75,7 \%$, sendo, portanto, necessária uma representação gráfica tridimensional como mais adequada.

Com o uso das estimativas dos coeficientes de ponderação, foram descartados 28 descritores quantitativos. Verificou-se que o primeiro caráter indicado foi G10 $(0,4397)$, seguido pelos descritores G21 $(0,4521)$, G2 $(0,5104)$, G20 $(0,5538), G 19(0,7895)$, respectivamente, cujos maiores autovetores em módulo ocorreram nos componentes principais 33, 3231 e 30, respectivamente.

Nas estimativas dos autovalores associados aos componentes principais dos descritores de textura das sementes, três componentes principais explicaram $83,62 \%$ da variabilidade observada, onde o primeiro componente foi responsável por $52,18 \%$ da variação, o segundo componente por $20,94 \%$ e o terceiro componente por $10,50 \%$ desta variação. Foram selecionados seis descritores de textura sendo T3, T7, T11, T15, T19 e T25, ou seja, dos 27 descritores analisadas 21 (77,77\%), eram redundantes (Tabela 3 ).

TABELA 3. Estimativas dos autovalores associados aos componentes principais (CP) e suas variâncias relativas e acumuladas, obtidas dos 27 caracteres de textura avaliados em sementes de maracujazeiro azedo

\begin{tabular}{rccc}
\hline CP & Autovalor & $\begin{array}{c}\text { Variância } \\
\text { relativa }\end{array}$ & $\begin{array}{c}\text { Variância } \\
\text { acumulada }\end{array}$ \\
\hline 1 & 14,09 & 52,18 & 52,18 \\
2 & 5,65 & 20,94 & 73,12 \\
3 & 2,84 & 10,50 & 83,62 \\
4 & 1,16 & 4,30 & 87,93 \\
5 & 0,93 & 3,46 & 91,39 \\
6 & 0,80 & 2,95 & 94,34 \\
7 & 0,53 & 1,97 & 96,31 \\
8 & 0,33 & 1,23 & 97,54 \\
9 & 0,24 & 0,90 & 98,44 \\
10 & 0,16 & 0,60 & 99,04 \\
11 & 0,09 & 0,33 & 99,38 \\
12 & 0,06 & 0,21 & 99,59 \\
13 & 0,04 & 0,15 & 99,74 \\
14 & 0,02 & 0,09 & 99,83 \\
15 & 0,02 & 0,07 & 99,90 \\
16 & 0,01 & 0,03 & 99,93 \\
17 & 0,01 & 0,03 & 99,96 \\
18 & 0,01 & 0,02 & 99,98 \\
19 & 0,00 & 0,01 & 99,99 \\
20 & 0,00 & 0,01 & 99,99 \\
21 & 0,00 & 0,00 & 100,00 \\
22 & 0,00 & 0,00 & 100,00 \\
23 & 0,00 & 0,00 & 100,00 \\
24 & 0,00 & 0,00 & 100,00 \\
25 & 0,00 & 0,00 & 100,00 \\
26 & 0,00 & 0,00 & 100,00 \\
27 & 0,00 & 0,00 & 100,00 \\
\hline & & &
\end{tabular}


Kara et al. (2013), utilizaram as propriedades de tamanho e forma de sementes que foram determinadas usando o método de processamento de imagem em fotografia digital para agrupar 12 variedades de feijão na Turquia. Os autores também verificaram que os dois primeiros componentes explicaram $96,1 \%$ da variação total, com a formação de quatro grupos.

Com o uso das estimativas dos coeficientes de ponderação, foram descartados 21 descritores quantitativos de textura. O descritor T17, apresentou 0 maior coeficiente de ponderação em módulo com o último componente principal ($0,515)$, seguido pelos descritores T20 $(-0,743)$, T10 $(-0,802)$, T22 $(0,431)$, T8 ($0,440)$, respectivamente, cujos maiores autovetores em módulo ocorreram nos componentes principais $27,26,25,24,23,22$ respectivamente.

Em geral foram selecionados cinco descritores de cor, seis descritores de geometria e seis de textura. Totalizando 17 descritores selecionados, representando um descarte de $82,11 \%$ em relação a total dos descritores analisados. Foram selecionados os seguintes descritores: cor abaixo do otsu canal vermelho (C3), cor abaixo do otsucielab a (C4), cor cielab b (C15), cor cielab dispersão de b (C18), cor matiz (C26), geometria complexidade da forma (G8), geometria diâmetro lateral (G14), geometria esfericidade de forma modificada (G18), geometria perímetro convexo (G23), geometria quociente de aspecto (G24), geometria retângulos circunscritos maior área (G25), textura haralick correlação (T3), textura haralick homogeneidade (T7), textura haralick média, textura lawsle (T11), textura lawsrw (T15),textura runlenghtglnu (T19) e textura runlenghtshge (T25). Esses 17 descritores podem ser utilizados em estudos de divergência genética na cultura do maracujazeiro. Marostega et al. (2017) estimou a divergência genética entre acessos Passiflora com base nas características morfofisiológicas das sementes

De acordo com Pinto et al. (2010), é possível a eliminação de descritores sem perda de informação, pois os mesmos podem estar correlacionados a outros que permaneceram na análise. Dessa forma, os seis descritores selecionados de cor, seis de geometria e cinco de textura das sementes, que nunca foram mensuradas antes ou somente em situações específicas podem ser medidas com maior frequência e são capazes de contribuir para o estudo de divergência genética.

Estes descritores são úteis como descritores adicionais na avaliação da variabilidade genética entre as FIC no maracujazeiro azedo, pois além de serem precisos é possível analisar um número alto de descritores por vez, economizando tempo e também com menos gastos.

$\mathrm{Na}$ Turquia, foram utilizadas sementes para discriminar oito variedades de pimenta. Para isso realizaram a aquisição de imagem digital usando um scanner em uma resolução de 1200 dpi e determinaram as características de cor, forma e textura das sementes de pimenta (Kurtulmus et al., 2016). Os autores verificaram que das 257 características das sementes obtidas via análise digital de imagens, foi necessário somente 10 para a classificação das variedades de pimenta com alta acurácia. Assim das 136 variáveis analisadas apenas 17 contribuíram para discriminar e estimar a divergência entre as FIC.

\section{CONCLUSÃO}

Foi possível reduzir o número de descritores de sementes, sendo selecionados cinco de cor, seis de textura e seis de geometria. Os descritores de sementes selecionados podem ser utilizados em estudos de divergência genética no maracujazeiro azedo. A análise digital de imagem é uma ferramenta viável e eficiente na mensuração de descritores de sementes no maracujazeiro azedo. 


\section{AGRADECIMENTOS}

À CAPES pela concessão da bolsa de mestrado e a Fundação de Amparo à Pesquisa de Mato Grosso (Fapemat) pelo financiamento do projeto de pesquisa.

\section{REFERÊNCIAS}

ANDRADE, D. B.; OLIVEIRA A. S.; OLIVEIRA C. A. R. M.; SILVA M. A. S. Detection of green seeds in soybean lots by the seed analysis system (sas). International Journal of Current Research, v.8, n.2, p.26462-26465, 2016. Disponível em: $<$ http://www.journalcra.com/sites/default/files/12927.pdf>.

CRUZ, C. D. GENES - a software package for analysis in experimental statistics and quantitative genetics. Acta Scientiarum, v.35, n.3 p.271-276, 2013. http://dx.doi.org /10.4025/actasciagron.v35i3.21251.

CRUZ, C. D.; REGAZZI, A. J.; CARNEIRO, P. C. S. Modelos biométricos aplicados ao melhoramento genético. 4. ed. rev. Viçosa: UFV, 2012. 514 p.

FIORANI, F.; SCHURR, U. Future scenarios for plant phenotyping. Annual Review of Plant Biology, v.64, p.267-91, 2013. https://doi.org/10.1146/annurev-arplant050312-120137.

GUSTIN, J. L.; SETTLES, A. M. Seed phenomics. In: Fritsche-Neto, R.; Borém, A. Phenomics: How Next-Generation Phenotyping is Revolutionizing Plant Breeding. Viçosa, 2015. v.1, p 65-79.

JOLLIFFE, I. T. Discarding variables in a principal component analysis. I: Artificial data. Applied Statistics, v.21, n.2, p.160-173, 1972.

JOLLIFFE, I. T. Discarding variables in a principal component analysis. II: Real data. Applied Statistics, v.22, n.1, p.21-31, 1973.

KARA, M.; SAYINCI, B.; ELKOCA, E.; ÖZTÜRK, .; ÖZMEN, T. B. Seed size and shape analysis of registered common bean (Phaseolus vulgaris L.) cultivars in Turkey using digital photography. Tarım Bilimleri Dergisi. v.19, p. 219-234. 2013. Disponível em: http://dergiler.ankara.edu.tr/dergiler/15/1814/19162.pdf> DOI:10. 1501/Tarimbil_0000001247.

KRAUSE, W.; VIANA, A. P.; CAVALCANTE, N. R.; AMBRÓSIO, M.; SANTOS, E. A.; VIEIRA, H. D. Digital phenotyping for quantification of genetic diversity in inbred guava (Psidium guajava) families, Genetics and Molecular Research, v.16, n.1, p.1-11, 2017. http://dx.doi.org/10.4238/gmr16019474.

KURTULMUŞ, F.; LKNUR ALIBAŞ, I.; KAVDIR, I. Classification of pepper seeds using machine vision based on neural network, Int J Agric \& Biol Eng, v.9, n.1 p.5154, 2016. Disponível em: <http://ijabe.org/index.php/ijabe/article/view/1790/pdf> doi: 10.3965/j.ijabe.20160901.1790.

LÚCIO, A. D.; STORCK, L.; KRAUSE, W.; GONÇALVES, R, Q.; NIED, A. H. Relações entre os caracteres de maracujazeiro-azedo. Ciência Rural, v.43, n.2, p.225-232, 2013. https://dx.doi.org/10.1590/S0103-84782013000200006. 
MARDIA, K. V.; KENT, J. T.; BIBBY, J. M. Multivariate analysis. Academic Press, 1979. v.24, p 520.

MAROSTEGA, T. N; ARAUJO, L. M; LUZ, P. B; NEVES, L. G; BARELLI, M. A. Genetic diversity of passiflora accessions based on morphophysiological seed descriptors. Revista Brasileira de Fruticultura, v.39, n.5, p.1-9. 2017. http://dx.doi.org/10.1590/0100-29452017365.

MEDINA, W; SKURTYS, O; AGUILERA, J. M. Study on image analysis application for identification Quinoa seeds (Chenopodium quinoa Willd) geographical provenance. LWT - Food Science and Technology, v.43, n.2, p.238-246. 2010. https://doi.org/10.1016/j.Iwt.2009.07.010.

PINTO, C. A. G.; CARVALHO, M. L. M.; ANDRADE, D. B.; LEITE, E. R.; Chalfoun, I. Image analysis in the evaluation of the physiological potential of maize seeds. Revista Ciência Agronômica, v.46, n.2, p. 319-328, 2015. http://dx.doi.org/ 10.5935/1806-6690.20150011.

PINTO, J. F. N.; REIS, E. F.; FALEIRO, F. G.; BARBOSA, E. C. C.; NUNES, H. F.; PINTO, JEEDER, F. N. Seleção de descritores vegetativos para caracterização de acessos de guariroba (Syagrus oleracea (Mart.) Becc.). Revista Brasileira de Fruticultura, v.32, n.3, p.832-840, 2010. http://dx.doi.org/10.1590/S010029452010005000094.

SANTOS, T. T.; YASSITEPE, J. E. DE C. T., Fenotipagem de plantas em larga escala: um novo campo de aplicação para a visão computacional na agricultura., In: MASSRUHÁ, S. M. F. S.; LEITE, M. A. DE A.; LUCHIARI JUNIOR, A.; ROMANI, L. A. S. (Ed.). Tecnologias da informação e comunicação e suas relações com a agricultura. Brasília, DF: Embrapa, 2014, v1. p. 85-100.

SILVA, V. N.; GOMES JUNIOR, F. G.; CICERO, S. M. Computerized imaging analysis of seedlings for assessment of physiological potential of wheat seeds. Revista brasileira de sementes, v.34, n.4, p.589-596, 2012. http://dx.doi.org/10.1590/S0101-31222012000400009.

VENORA, G.; GRILLO, O.; RAVALLI, C.; CREMONINI, R. Identification of Italian landraces of bean (Phaseolus vulgaris L.) using an image analysis system. Scientia Horticulturae, v.121, n.4, p.410-418, 2009. https://doi.org/10.1016/j.scienta. 2009.03.014. 